\title{
Title: The Productive Anarchy of Scientific Imagination
}

\author{
Forthcoming in Philosophy of Science
}

\begin{abstract}
Imagination is important for many things in science: solving problems, interpreting data, designing studies, etc. Philosophers of imagination typically account for the productive role played by imagination in science by focusing on how imagination is constrained, e.g., by using self-imposed rules to infer logically, or model events accurately. But the constraints offered by these philosophers either constrain too much, or not enough, and they can never account for uses of imagination that are needed to break today's constraints in order to make progress tomorrow. Thus, epistemology of imagination needs to make room for an element of epistemological anarchy.
\end{abstract}

Author Details

Name: Michael T. Stuart

Email: mike.stuart.post@gmail.com

ORCID: 0000-0002-4165-2641

Affiliation: Department of Philosophy, University of Geneva

Acknowledgements: I would like to thank the audience of our PSA symposium on scientific imagination for helpful feedback, Jamie Shaw for comments on the paper, and my fellow symposiasts Steven French, Alice Murphy and Fiora Salis for their ongoing support, friendship, and detailed comments. I would also like to thank the Swiss National Science Foundation for Funding. 


\section{Introduction}

Imagination is now "recognized as a source of belief and even knowledge" (Wansing 2017, 2843). This recognition has led to an "explosion of philosophical interest" in the imagination (Funkhouser and Spaulding 2009, 291). ${ }^{1}$ There are many exciting open questions in the epistemology of scientific imagination: Is imagination best characterized as an ability, a character trait, a mental state, or a process? Can imagination produce all or only some of the kinds of epistemological desiderata in science, e.g., propositional knowledge, knowledge how, understanding, explanation, and justification? What makes one scientist a better imaginer than another? Can good scientific imagination be taught?

A claim that enjoys "near universal agreement" is that what we imagine is not constrained by how the world is (Kind 2016b, 1-3): we can imagine false, and perhaps even impossible things. Therefore, we cannot expect uses of imagination to inform us truthfully about the real world, in general. But we are free to constrain our imagination if we like, and it is only appropriately constrained uses of imagination that are epistemically trustworthy. Amy Kind puts the point this way:

There are indeed many different uses to which imagination can be put, but when we constrain our imaginings to fit the facts of the world as we know them, we are using

\footnotetext{
${ }^{1}$ Seminal contributions include Byrne (2005), Currie and Ravenscroft (2002), Nichols (2006), Nichols and Stich (2003), Walton (1990), Kind (2016a), and Kind and Kung (2016).
} 
an epistemic procedure that is much more akin to scientific experimentation than it is to mere flights of fancy. Although our imaginative experimentation will not be fool proof, neither is scientific experimentation. But in both cases, when we proceed cautiously, the beliefs that we arrive at will...usually be justified. (2018, 244)

Similarly, Gregory Currie claims that "constraints are crucial to understanding how learning from imagination is possible" $(2016,407)$. He provides an example:

We have some capacity to estimate whether we will be able to climb from that branch of a tree to the one above, without actually having to try it out. Perhaps we do this by imagining the act of climbing. How this might be done in such a way as to provide reliable information is not well understood, but it could hardly be done at all if imagining moving failed to respect the constraints on actual movement. (411)

Peter Kung writes, If imagination is always as unconstrained as it is in its transcendent [perfectly free] use, then it is hard to see how imagination could provide justification... The obvious response to the skeptical challenge is to locate constraints in imagination, constraints such that, when they are in effect, imagination hews to the metaphysically possible. Skeptics charge that this challenge cannot be met. Antiskeptics offer competing theories of these constraints. $(2016,438)$.

For Kind, "the sorts of cases in which imagining plays an epistemic role can be easily distinguished from the sorts of cases in which it does not" precisely by identifying which 
uses are constrained $(2018,239)$. Relatedly, what separates creative geniuses like Nikola Tesla and Temple Grandin from more mediocre imaginers is that geniuses are better at setting the right constraints, and abiding by them (Kind 2018).

As Kung claims, the consequence of this view is that epistemologists of imagination must find the set of constraints, adherence to which will convert imagination into a reliable guide to reality.

In the next section, I present two popular strategies for identifying such constraints. I will then ask whether the constraints discovered by these strategies could ever exhaust the epistemology of (scientific) imagination. I answer in the negative: constraint-based views produce constraints that rule-out too much or don't rule-out enough. More importantly, they cannot explain the "anarchic" uses of imagination that we need to make useful mistakes and break out of false scientific dogma.

\section{Two Strategies for Identifying Constraints on Imagination}

The first strategy for identifying constraints takes its cue from logic. Reliable uses of imagination are constrained by the rules of good inference-making, e.g., using only true premises and making only valid inferences. Some version of this strategy is pursued by Berto (2017, 2018), Chalmers (2002), Giordani (2018), Kung (2010), Lewis (1973), Nichols and Stich (2003), Norton (2004), Stalnaker (1968), Van Inwagen (1998), Wansing (2017), Williamson (2016) and Yablo (1993).

To illustrate this approach, consider the Gettier case. Several philosophers have presented this as an exercise of imagination that increases our knowledge, either about knowledge 
itself or the concept of knowledge. It proceeds by a modal argument. And as long as the argument is valid, and the premises are true, then the exercise of imagination produces knowledge.

The second strategy takes its cue from the literature on scientific modelling. Here, reliable uses of imagination are those whose representations of some target system are accurate, and whose dynamic evolutions of those representations are constrained in terms of how well they mimic the dynamics of the target system. ${ }^{2}$ These are the same constraints we place on scientific models. Some version of this strategy is pursued by Byrne (2005), Gregory (2010), Kung (2010), Lam (2018), Miščević (1992, 2007) and Nersessian (1993, 2007).

To illustrate this approach, consider the well-worn example of trying to move a couch through a doorway. Here, if the imagined representation of the size and shape of the couch and doorway are accurate, and all the laws of nature that are relevant for the real system are also "operative" in the imagined case, then if we can get the couch through the doorway in imagination, we can do it in reality.

\footnotetext{
${ }^{2}$ E.g., Nersessian writes that model-based reasoning uses iconic representations that "are similar in degrees and aspects to what they represent, and are thus evaluated as accurate or inaccurate. Operations on iconic representations involve transformations of the representations that change their properties and relations in ways consistent with the constraints of the domain" $(2007,132)$.
} 
On both strategies, we have two objects to be constrained: the content of imagination, and the way that content is manipulated. On the logic-based approach, we are restricted to using true or probable premises. On the modelling-based approach, we are restricted to accurate representations. For the manipulation of content, the logic-based approach restricts us to inferences that are valid or cogent, while the model-based approach restricts us to evolving the content according to dynamics that are sufficiently similar to those that govern the target system. When both the content and the manipulation of that content are appropriately constrained, knowledge does or may follow.

I want to ask how far such an epistemological strategy can take us. Despite the widespread focus on constraints in epistemology of imagination, as far as I know, there is no one who explicitly claims that a successful investigation into the constraints on imagination will provide an absolutely exhaustive epistemology of imagination. But there are several reasons to think that such a strong view is implicit in both constraint-identification strategies, due in both cases to the underlying epistemological framework adopted (logic or model-based reasoning). For one thing, logic and model-based reasoning do not admit of exceptions. There are no instances of good reasoning which logic should give up trying to explain. If an instance of good reasoning is found which cannot be captured by logic, logic must change to incorporate it, or we must deny that the reasoning was good after all. Likewise, if there is an instance of good scientific modelling that cannot be captured by our best epistemology of modelling, this again is not acceptable. Any constraint-based epistemology of imagination that will not admit of exceptions seeks to be exhaustive: for 
every use of imagination, it must provide an epistemological verdict, and it will do so in terms of constraints.

Another reason to think these two constraint-based epistemological approaches seek to be exhaustive comes from considering their tendency to generalize from simple cases (like jumping over streams and moving couches) to more complicated ones. Logicians typically don't concern themselves with the complex and piecemeal inferences made by scientists in their daily work. And philosophers working on scientific models often focus on textbook cases that allow them to ignore messy historical, cultural and cognitive details. Sometimes there are good reasons to focus on simple cases. I merely want to point out that when we pursue this strategy, it may appear that all the epistemologically relevant features can be exhaustively explained via reference to constraints, and this tempts us to think that this will also hold in more complex cases. Imagining that you can jump over a stream might be evidence that you can jump over that stream when you constrain your imagination so the stream's width and the trajectory of your jump are "realistic." But an additional argument is needed to justify the ampliative inference that, e.g., Williamson makes, according to which his view of imagination "does not predict that [imagination] will be cognitively reliable only for tasks just like those it evolved to serve. Its tendency to use something like rules of deductive logic is an example to the contrary, since they are quite generally truthpreserving" $(2016,122)$. Capturing all the relevant features of simple cases can cause us to believe that there are no further relevant features, and that our epistemology is exhaustive.

Still, to repeat, no one, as far as I know, explicitly claims that a constraint-based epistemology of imagination could tell us, for every epistemically successful use of 
imagination, why it succeeds. And this means that I am now going to argue against a strawperson. That's okay; it will be a useful strawperson if it tempers our optimism and prevents a serious philosophical error.

One problem with constraint-based views is that they provide constraints that are either too restrictive or too permissive. John D. Norton has made a similar argument against formal accounts of inference to the best explanation, argument by analogy, and the scientific value of experimental replication and simplicity (Norton forthcoming). The point translates easily. When we say that a representation has to be accurate, how accurate do we mean? If they must be extremely accurate, this will disqualify many uses of imagination we want to count as epistemically successful. If they must only be slightly accurate, many unsuccessful uses of imagination come out better than they are. This argument is based on existing constraints, so a critic can still reply that the right constraints are just around the corner. To address that counterargument, I want to focus on uses of imagination that everyone agrees are "good," but which break the "obvious" constraints we want to apply to imagination. To do this, I draw inspiration from the work of Paul Feyerabend.

\section{Imagination and Epistemological Anarchy}

Feyerabend has several arguments against the idea that we should constrain scientific thought. One is reactionary. Any philosopher who attempts to identify the "right" constraints on scientific reasoning can always be shown exemplary instances of science that break their favourite constraints, e.g., that we should be consistent, reason using valid argument forms, use accurate representations, not introduce ad hoc assumptions, etc. In 
Against Method, Feyerabend's main examples come from Galileo, but he gestures toward others including renormalization in quantum mechanics, Newton on gravity, Bohr's model of the atom, and aspects of special and general relativity (Feyerabend 1975, 40-6).

Feyerabend reminds us that his "examples do not criticize science; they criticize those who want to subject it to their simpleminded rules by showing the disasters such rules would create" $(1975,46)$. His famous catch phrase, "anything goes" really means nothing always goes. Put another way, "all methodologies, even the most obvious ones, have their limits" (1975, 23). The way he phrases this in The Tyranny of Science is even more congenial: anything goes “means only 'don't restrict your imagination' because a very silly idea can lead to a very solid result... You cannot foresee what kind of silly move will lead you to a new insight or to a new discovery.... And don't restrict your imagination by logic" (2011, 130-131).

A different argument of Feyerabend's tries to show that even if we could create a version of science that followed our best constraints, it would be inhuman. Such a science would have to be maintained through dogmatic education, teaching a particular set of methods to the exclusion of everything else. Educators would "mould the brains of the young until they have lost every ounce of imagination they might once have possessed" $(1975,160)$. If any trace of imagination survived such an education, it would have to be channeled away into non-scientific pursuits, and this would be a disaster $(1975,38)$. On a better arrangement, scientists would take up certain theories and methods of science only by choice, never dogma $(1975,162)$. Feyerabend's point is that universal constraints imply 
“dogmatism, lack of imagination, intolerance, and lack of free expression" (257), all of which are anathema to a properly functioning science and society.

Larry Laudan summarizes a common reaction to these two arguments: "To assert with Feyerabend that [anything goes] is to hold that there are no regularities about inquiry, that there are no facts of the matter about how to put questions to nature" $(1989,313)$. But Feyerabend was perfectly happy with normative epistemology of science, as long as it didn't claim to be exhaustive (e.g., Feyerabend 1991, 503). I want to point out that tendencies toward exhaustiveness now appear on the horizon of current epistemology of imagination. And it is important that such tendencies not produce norms for philosophical or scientific practice, because such norms would rob imagination of its ability to break us out of progress-impeding boxes.

To illustrate some of the above ideas, here are two examples.

Against the logic-based strategy for identifying constraints on imagination, consider Galileo's famous falling bodies thought experiment. Here, we imagine two objects of the same material (e.g., lead) but of different weights that are connected and dropped, say, from a tower. According to Aristotelians, this composite object should travel both faster and slower than the heavier object would have travelled on its own (because the composite object weighs more and therefore should fall faster, but on the other hand, the lighter object will "want" to move more slowly, which will produce a drag that will cause the composite object to fall more slowly than the heavier object alone). Since this is impossible, we should conclude that all objects of the same material composition (ignoring 
air resistance) fall at the same speed, viz., a speed independent of their weight. This is a famously invalid argument. Indeed, "logic was on the side of...Bellarmine and not on the side of Galileo" (Duhem, quoted in Feyerabend 1975, 133). Tamar Gender (1998) argues that it is invalid in the sense that even if the premises are true, the conclusion need not follow, as it is open to the Aristotelian to distinguish between the weights of united and unified entities, or to deny that composite objects have determinable weights (see also Brown 1986). If Galileo's use of imagination requires true premises and valid inferences to be epistemically approved, it must be counted as an epistemically poor use of imagination. But any account that makes such a claim faces a direct clash with powerful intuitions about what counts as good science, as Galileo's uses of imagination fueled a massive leap forward for science. Either we reject Galileo's use of imagination as part of sanctioned scientific progress, or we reject the idea that imagined scenarios should always follow the rules of logic.

One might reply that while Galileo's use of imagination was epistemically unjustified, the change it helped to usher in was epistemically positive, and this retrospectively justifies his use of imagination. An epistemic use of imagination might be "bad," but if it has certain consequences, its status can reverse. The problem with this reply is that logic does not have the resources to reverse judgments about particular inferences in this way: having positive consequences does not change anything about the structure of Galileo's inference. It does not change the truth value of the premises or the logical relations between the propositions, so it cannot change its logical status. Also, logic-based epistemologies aim to be prescriptive as well as retrospective. If we allow that future consequences can change the 
justificatory status of a use of imagination, we give up our right to say that any given use of imagination is justified or not, until we know all its consequences.

A second problem with this attempt to deal with Galileo's use of imagination is that it appeals to more general argumentative endeavours, of which Galileo's use of imagination forms a part. But current epistemologies of imagination tend to focus on specific cases and ask what constraints explain their epistemic quality, without making recourse to broader theoretical projects. If we allow broadening of focus, this would greatly increase the difficulty of pronouncing, for any given use of imagination in actual scientific practice, whether it is epistemically approved or not, until the full context has been identified and taken into account. That would be a serious limitation to the aims of any epistemology of imagination that aims to provide an epistemic verdict for any and all epistemic uses of imagination.

Perhaps Feyerabend is right, then, that the logician is one "who preaches to [scientists] about the virtues of clarity, consistency, experimental support (or experimental falsification), tightness of argument, 'honesty', and so on," while the right thing to do is for the scientist to disobey that logician and "imitate his predecessors in his own field who advanced by breaking most of the rules logicians want to lay on him" (Feyerabend 1975, 197).

The second example is Einstein's “chasing the light” thought experiment, which I think counts against any model-based epistemology of imagination that aims to be exhaustive. In this thought experiment, we imagine travelling at the speed of light, alongside a beam of 
light, and then ask ourselves what the lightwave would look like. After performing this exercise himself, Einstein claims he was able to draw conclusions that helped to inspire special relativity (Norton 2013). But to get to the conclusion of the thought experiment, we must violate constraints, such as having accurate representations of the target system that evolve realistically. First, if you travelled at the speed of light, you would explode, taking a substantial part of the Earth's crust with you (which is important because you can't see without eyes). Second, you are supposed to consider what a wave of light travelling parallel to you would "look" like, but human eyes can't "see" lightwaves. Overall, it's hard to identify a single accurate representation in the imagined portion of this thought experiment. Again, either Einstein was breaking rational constraints on imagination and thus imagining "wrongly," or, as I suspect, we should reject the constraint that imagined scenarios should be accurate if they are to produce knowledge. ${ }^{3}$

While the constraints on model-based reasoning might be in some sense less demanding and more cognitively realistic than formal deductive or inductive logic, they do consistently claim that accurate representations and faithful dynamics are required. As long as this is taken seriously, Feyerabend's reply seems apt: "a person trying to solve a problem whether in science or elsewhere must be given complete freedom and cannot be

\footnotetext{
${ }^{3}$ Presumably, Einstein did place some constraints on his imagination. But the question is not whether imagination should ever be constrained. The question is whether we should adopt epistemologies that attempt to explain the success of scientific imagination wholly in terms of constraint-following, and never in terms of constraint-breaking.
} 
restricted by any demands, norms, however plausible they may seem to the logician or the philosopher who has thought them out in the privacy of his study. Norms and demands must be checked by research, not by appeal to theories of rationality" $(1975,261)$. Einstein was not wrong to violate the constraints on good modelling, it is our urge to constrain that is wrong.

We are now in a position to present a reductio ad infinitum argument against constraintbased epistemologies of imagination that aim to be exhaustive. Suppose scientific imagination should be constrained in certain ways. Cases will be found where scientists should break those constraints, because doing so enabled progress. An opponent may accept this, and yet claim that there are exceptionless constraints on how often to break the constraints, or how far we are allowed to stretch them. However, exceptions to these metaconstraints on imagination should also be expected. All we need is a scientist who spent "too long" doing something that would appear irrational by the lights of our normative epistemology, and yet "succeeded" (where "success" is defined by that same epistemology). Meta-meta constraints could now be proposed, which detail how often or by how much the meta-constraints can be broken. This would preserve the rationality of imagination by ensuring that it still conforms to a set of exhaustive constraints. But again, cases will be found (or can be imagined) that violate the meta-meta constraints, which are nevertheless "successful." Thus, we should not expect there to be an exceptionless set of 
constraints (or meta ${ }^{\mathrm{n}}$-constraints) for properly operating scientific imagination that can account for all successful uses of imagination in science. ${ }^{4}$

This paper is not a plea to bring daydreaming and fantasy into science education (although that might not be a bad idea). I have focused on epistemic uses of scientific imagination that can be separated from daydreams at least in the sense that they are intended to tell us something about the world. Galileo's and Einstein's imaginings clearly have this function, despite breaking typical constraints on "good" reasoning. Thus, even when we are focusing purely on reality-oriented scientific imagination, it is still the case that we should not seek an exhaustive set of constraints which guarantee the proper epistemic functioning of imagination.

\section{Concluding Remarks}

Imagination can help us to make epistemically productive mistakes by introducing new ideas that weren't carefully inferred from previous knowledge. Imagination can be epistemically progressive for science even when it's being used in apparently irrational ways (e.g., by breaking constraints on good inference-making), and sometimes because it is used in these ways. Therefore, we should not treat imagination as something that must preserve truth or accuracy in order to further our epistemic projects. "Imagination is much more than a faculty for evoking images which double the world of our direct perceptions: it

\footnotetext{
${ }^{4}$ Again, this is not to say that we can't ever identify context-specific constraints that are helpful in certain cases.
} 
is a distancing power thanks to which we represent to ourselves distant objects and we distance ourselves from present realities" (Crapanzano 2004, 19). "Imagination allows one to be playful, to play with different hypotheses, and to play with different ways of making objects" (Gaut 2003, 160-1). This playful distancing power can be necessary for epistemic progress in science, and to exercise it, we sometimes have to break otherwise helpful constraints on scientific reasoning.

These remarks about the role of scientific imagination fit into a much wider debate. At some point, scientists began presenting their work as "objective" (Daston and Galison 1992, 2007), downplaying the input of subjective factors until faculties like the imagination were completely excluded for not being sufficiently constrained by reality (Daston 2001). Eventually, "restrained" imagination was supposed to take the place of what Lorraine Datson refers to (tongue-in-cheek) as the "wild imagination that tyrannized pregnant women, religious fanatics, or mesmerized convulsionnaires" (Daston 2001, 88). Philosophers like Feyerabend fought back against this "rationalizing" impulse, arguing that a perfectly "objective," rule-governed science would not be science as we know it, nor would it be an optimal science. That lesson has been fully digested by the history and philosophy of science, so that now we only ever claim to provide some constraints on imagination to make it more rational. However, this is in tension with the underlying epistemological tendencies toward exceptionlessness that can be found in logic and modelbased epistemologies of reasoning. These are tendencies that we must resist.

In a dialogue with himself, Feyerabend once asked whether he was required to provide a positive epistemological account of science, after having criticized the exhaustive 
aspirations of the so-called "rationalists." He replied that "a world without monsters [rationalists] is better than a world with them, and 'reasonable people' will celebrate their departure and hope that nothing like them will ever turn up again" $(1991,518)$. This might suffice. However, a positive claim is just around the corner. Imagination can lead us away from the truth, and so, sometimes, it should be constrained so that it preserves what truth or accuracy we already (think we) possess. But this is only a fraction of the epistemologically beneficial roles imagination can play in science. "Knowledge," Bacon claimed, "whilst it lies in aphorisms and observations, remains in a growing state; but when once fashioned into methods, though it may be further polished, illustrated and fitted for use, is no longer increased in bulk and substance" $(1605,51)$. Imagination is so important for science because it can break us out of what our best theories tell us. And this is crucially important because our best theories might be wrong. Any epistemology that seeks to constrain away this ability strips the imagination of what might be its most important epistemic function. 


\section{References}

Bacon, Francis. 1605/1898. The Dignity and Advancement of Learning. Repr. in J. Devey (ed.). The Physical and Mathematical Works of Lord Bacon. London: George Bell and Sons.

Berto, Francesco. 2017. "Impossible worlds and the logic of imagination." Erkenntnis 82: 1277-97.

-- -- -- 2018. “Taming the Runabout Imagination Ticket.” Synthese. https://doi.org/10.1007/s11229-018-1751-6.

Brown, James R. 1986. "Thought Experiments since the Scientific Revolution.” International Studies in the Philosophy of Science 1: 1-15.

Byrne, Ruth. 2005. The Rational Imagination. Cambridge: MIT Press.

Chalmers, David. 2002. "Does Conceivability Entail Possibility?” Pp. 145-99 in T. S. Gendler and J. Hawthorne (eds.). Conceivability and Possibility. Oxford: OUP.

Crapanzano, Vincent. 2004. Imaginative Horizons. Chicago: University of Chicago Press.

Currie, Gregory. 2016. “Imagination and Learning.” In Kind 2016a, 407-19.

Currie, Gregory and Ian Ravenscroft. 2002. Recreative minds. Oxford: OUP.

Datson, Lorraine. 2001. "Fear and Loathing of the Imagination in Science." In Science and Culture, ed. Peter Galison, Stephen R. Graubard, and Everett Mendelsohn, 73-96. London: Transaction Publishers. 
Daston, Lorraine and Peter Galison. 1992. “The Image of Objectivity.” Representations 40: 81-128.

-- -- -- 2007. Objectivity. New York: Zone Books.

Feyerabend, Paul. 1975/1993. Against Method, 3rd edition. London: Verso.

-- -- -- 1991. “Concluding Unphilosophical Conversation.” In Beyond Reason, ed. Gonzalo Munévar, 487-572. Dordrecht: Springer.

-- -- -- 2011. The Tyranny of Science, ed. Eric Oberheim. Cambridge: Polity Press.

Gaut, Berys. 2003. "Creativity and Imagination.” In The Creation of Art, ed. Berys Gaut and Paisley Livingston, 148-73. Cambridge: Cambridge University Press.

Gendler, Tamar S. 1998. "Galileo and the Indispensability of Scientific Thought Experiment.” British Journal for the Philosophy of Science 49: 397-424.

Giordani, Alessandro. 2018. “Axiomatizing the Logic of Imagination.” Studia Logica. https://doi.org/10.1007/s11225-018-9810-z.

Gregory, Dominic. 2010. “Conceivability and Apparent Possibility.” In Modality:

Metaphysics, Logic, and Epistemology, ed. Bob Hale and Aviv Hoffmann, 319-41. Oxford: OUP

Kind, Amy. 2016a. The Routledge Handbook of Philosophy of Imagination, New York: Routledge.

-- -- -- 2016b. “Introduction: Exploring Imagination.” In Kind 2016a, 1-11. 
-- -- -- 2018. “How Imagination Gives Rise to Knowledge.” In Perceptual Memory and Perceptual Imagination, ed. Fiona Macpherson and Fabian Dorsch, 227-246. New York: Oxford University Press.

Kind, Amy and Peter Kung (eds.). 2016. Knowledge through imagination. Oxford: Oxford University Press.

Kung, Peter. 2010. "Imagining as a guide to possibility.” Philosophy and Phenomenological Research 81: 620-663.

-- -- -- 2016. “Imagination and Modal Knowledge.” In Kind 2016a, 437-450.

Lam, Derek. 2018. “Is Imagination Too Liberal for Modal Epistemology?” Synthese 195: 2155-2174.

Laudan, Larry. 1989. “For Method: or, Against Feyerabend.” In An Intimate Relation: Studies in the History and Philosophy of Science Presented to Robert E. Butts on His 60th Birthday, ed. James Robert Brown and Jürgen Mittelstrass, 299-317. Dordrecht: Springer.

Lewis, David. 1973. Counterfactuals. Oxford: Basil Blackwell.

Miščević, Nenad. 1992. "Mental Models and Thought Experiments.” International Studies in the Philosophy of Science 6: 215-226.

-- -- -- 2007. "Modelling Intuitions and Thought Experiments." Croatian Journal of Philosophy VII: 181-214. 
Nersessian, Nancy. 1993. "In the Theoretician's Laboratory: Thought Experimenting as Mental Modeling." Proceedings of the Philosophy of Science Association 2: 291301.

-- -- -- 2007. “Thought Experiments as Mental Modelling: Empiricism without Logic." Croatian Journal of Philosophy VII: 125-161.

Nichols, Shaun. 2006. Architecture of the Imagination. Oxford: Clarendon Press.

Nichols, Shaun and Stephen Stich. 2003. Mindreading. Oxford: Oxford University Press. Norton, John D. 2004. “On Thought Experiments: Is There More to the Argument?” Philosophy of Science 71: 1139-1151.

-- -- -- 2013. “Chasing the Light: Einstein's Most Famous Thought Experiment.” In Thought Experiments in Philosophy, Science and the Arts, ed. Mélanie Frappier, Letitia Meynell, and James Robert Brown, 123-140. New York: Routledge.

-- -- -- Forthcoming. The Material Theory of Induction.

Funkhouser, Eric and Shannon Spaulding. 2009. "Imagination and Other Scripts." Philosophical Studies 143: 291-314.

Stalnaker, Robert. 1986. "Possible Worlds and Situations." Journal of Philosophical Logic 15: 109-123.

Van Inwagen, Peter. 1998. "Modal Epistemology.” Philosophical Studies 92: 67-84.

Walton, Kendal. 1990. Mimesis as Make-Believe. Cambridge: Harvard University Press. 
Wansing, Heinrich. 2017. "Remarks on the Logic of Imagination. A Step Towards Understanding Doxastic Control through Imagination.” Synthese 194: 2843-2861.

Williamson, Timothy. 2016. “Knowing by imagining.” In Kind and Kung 2016, 113-23.

Yablo, Stephen. 1993. "Is Conceivability a Guide to Possibility?” Philosophy and Phenomenological Research 53: 1-42. 